\title{
Working
}

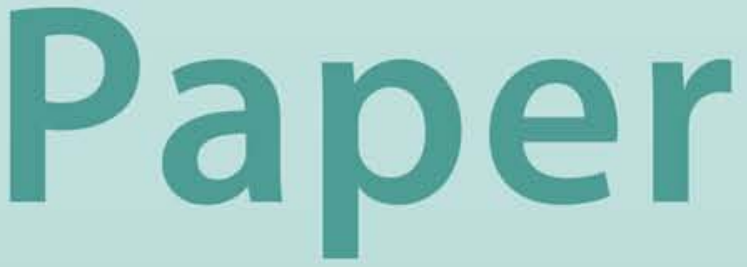




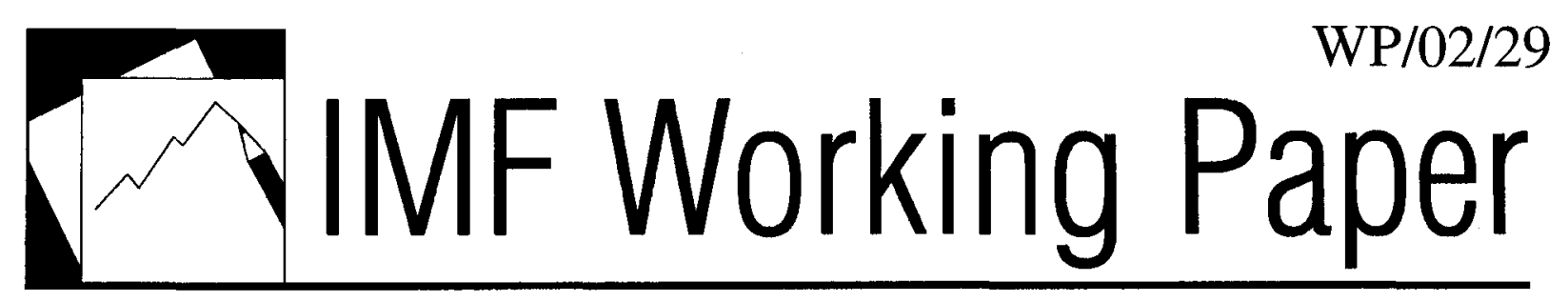

A Fiscal Theory of the Currency Risk
Premium and of Sterilized Intervention

Michael Kumhof and Stijn Van Nieuwerburgh 


\title{
IMF Working Paper
}

Research Department

\section{A Fiscal Theory of the Currency Risk Premium and of Sterilized Intervention}

\author{
Prepared by Michael Kumhof and Stijn Van Nieuwerburgh ${ }^{*}$ \\ Authorized for distribution by Ashoka Mody
}

February 2002

\begin{abstract}
The views expressed in this Working Paper are those of the author(s) and do not necessarily represent those of the IMF or IMF policy. Working Papers describe research in progress by the author(s) and are published to elicit comments and to further debate.
\end{abstract}

This paper develops a dynamic stochastic general equilibrium monetary portfolio choice model that accomplishes two objectives. First, it provides a theory of currency risk premia based on a weak and plausible form of fiscal nonneutrality. Domestic and foreign bonds become imperfect substitutes, the uncovered interest parity condition is replaced with a portfolio balance equation, and the central bank can separately choose the growth rate of its nominal anchor and the domestic bond interest rate. Second, it can turn be shown that, and how, sterilized intervention affects equilibrium allocations and prices.

JEL Classification Numbers: E43, E52, F41, G11

Keywords: Sterilized intervention, fiscal non-neutrality, currency risk premium, portfolio balance theory

Authors' E-Mail Address: MKumhof@imf.org; Svnieuwe@hotmail.com

"Michael Kumhof: Research department, IMF and Assistant Professor at Stanford University; Stijn Van Nieuwerburgh: Ph.D.Candidate at Stanford University. The authors would like to thank Guillermo Calvo, Ken Judd, Carmen Reinhart, Ken Rogoff, Tom Sargent, Martin Schneider, Stephen Turnovsky and seminar participants at the IMF, the 2001 LACEA meetings in Uruguay, and Stanford's Marco lunch group for helpful comments. 


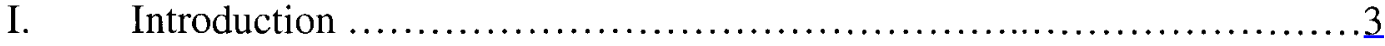

II. The Benchmark Case: Fiscal Neutralit ............................... and Uncovered Interest Parity

A. Households.................................................

B. Government..............................................

C. Equilibrium and Balance of Payments...........................14

D. Monetary Policy..............................................

a. Stock Operations....................................

b. Money Growth Policies ............................19

III. Fiscal Nonneutrality and Portfolio Balance...........................20

A. Government...................................................

B. Households..............................................23

C. Equilibrium and Balance of Payments........................23

D. Monetary Policy ...............................................

a. Stock Operations................................

b. Money Growth and Interest Rate Policies..................31

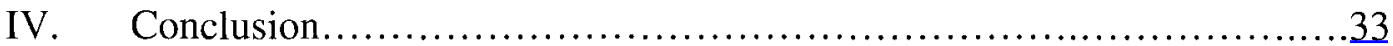

Text Figures:

1. Mexico-Foreigners' Holdings of Peso Denominated Government

Debt as \% of Total Peso Denominated Government Debt.................8

2. Temporary Money Growth Reduction under Fiscal Neutrality.............19

3. Portfolio Shares and Exchange Rate Volatility...........................29

4. Temporary Reduction in the Money Growth Rate....................... 32

5. Temporary Increase in the Domestic Interest Rate .......................33

Appendices:

I. Returns on Assets..............................................

II. Value Function-No Aggregate Exchange Risk..........................36

III. Value Function-Aggregate Exchange Risk.............................39

References............................................................... 41 


\section{INTRODUCTION}

This paper presents a dynamic stochastic general equilibrium monetary portfolio choice model of a small open economy whose central bank targets the growth rate of base money. Several of our assumptions are based on emerging markets environments. This includes the introduction of a weak and plausible form of fiscal nonneutrality, which implies that the uncovered interest parity condition is replaced with a portfolio balance equation and a fiscal theory of the currency risk premium. In this environment the domestic nominal interest rate becomes a second independent instrument of monetary policy and sterilized foreign exchange intervention affects equilibrium allocations and prices.

The paper is motivated by a curious tension between economic theory and practice on the question of sterilized intervention, most notably in emerging markets. In that group of countries central bankers routinely conduct open market operations in domestic currency debt with the intention of affecting interest rates and real activity. Their thinking might be taken to reflect older, partial equilibrium versions of portfolio balance theory such as Branson and Henderson (1985). But the economics profession, both theorists and empiricists, has been challenging the validity of such models for some time. We begin by summarizing this critique, and then go on to introduce our model.

The standard reference of modern open economy macroeconomics, Obstfeld and Rogoff (1996), dismisses portfolio balance theory as partial equilibrium reasoning because it does not take the government budget constraint into account. This point is made most comprehensively in an important paper by Backus and Kehoe (1989). ${ }^{1}$ They show that under complete asset markets, or under incomplete asset markets and a set of spanning conditions, changes in the currency composition of government debt require no offsetting changes in monetary and fiscal policies to both meet the government budget constraint and

\footnotetext{
1 Other references include: Sargent and Smith (1988) on the irrelevance of open market operations in foreign currencies; Chamley and Ptolemarchakis (1984), Sargent and Smith (1987), and Wallace (1981) on the irrelevance of domestic open market operations.
} 
leave private budget constraints unaffected. Consequently this 'strong form' of intervention is irrelevant for equilibrium allocations and prices. This result does not depend on Ricardian equivalence, monetary neutrality, or the law of one price, and can be shown using only an arbitrage condition. The authors then go on to argue that weaker forms of government intervention in asset markets generally require changes in monetary and/or fiscal policy to meet the government budget constraint. Because the impact of such 'weak form' interventions can as easily be attributed to these monetary and/or fiscal changes as to the intervention per se, sterilized intervention cannot be considered a separate, third policy instrument.

When the question of the efficacy of sterilized intervention is posed in this most general form, the results of Backus and Kehoe (1989) are very powerful. However, as these authors point out themselves, this leaves open the narrower but practically very important question of precisely how 'weak form' interventions affect the economy. The answer to this question requires taking a stance on the precise form of other government policies. In this context, one important consideration is that fiscal policy is generally not used as a short-term instrument to affect asset market equilibria. It is therefore plausible to rule out fiscal behavior that can respond arbitrarily to asset market interventions, and instead to consider only tax and spending rules whose form is independent of such interventions. We can then ask how sterilized intervention affects equilibrium allocations and prices conditional on the precise form of these rules. In other words, we ask whether sterilized intervention is effective as a second independent instrument of monetary policy. This is in fact a nontrivial exercise, because several important papers such as Obstfeld (1982) and Grinols and Turnovsky (1994) have given a negative answer to that question. They show that, once a monetary policy rule such as our money growth rule is specified, sterilized intervention has no further effects on asset market equilibria. Domestic and foreign bonds are perfect substitutes so that a version of uncovered interest parity holds. In this paper we show that these results depend on the specific form of the fiscal policy rule used by these 
authors, namely lump-sum redistribution of all government net revenue. While this is a convenient and frequently used assumption, it is also very strong, and we contend that in many real world cases it is not very descriptive of actual government behavior. When it is replaced by a weak and very plausible form of fiscal spending nonneutrality, sterilized intervention becomes an effective second instrument of monetary policy. Our paper explores the nature of its effects in general equilibrium.

The model assumes a stochastic money supply process which generates exchange rate volatility. Domestic currency denominated government issued liabilities therefore generate a stochastic seigniorage flow, and in partial equilibrium this would give rise to currency risk for private asset holders. In general equilibrium the key assumptions concern the use of this seigniorage by the government. In discussing the benchmark case of lump-sum redistribution to households, we confirm that currency risk is indeed absent in general equilibrium and that uncovered interest parity must hold. We then introduce fiscal spending nonneutrality. In particular, the government adjusts its real spending plans according to the realization of seigniorage shocks, in an economy where government spending does not enter private utility. In this case domestic currency denominated assets are risky even in general equilibrium. They are imperfect substitutes for foreign currency denominated bonds and their portfolio share is determined by a portfolio balance equation.

The focus of this paper on emerging markets is also justified on empirical grounds. As mentioned above, economists have questioned the effectiveness of sterilized intervention not only theoretically but also empirically. Edison (1993) is a good summary of the latter, but her evidence is limited to developed countries. The evidence for emerging markets summarized by Montiel (1993) is thinner but it does suggest some effectiveness of sterilized intervention. A key precondition for this is imperfect substitutability between domestic and foreign currency denominated bonds. An important paper by Bansal and Dahlquist (2000) presents valuable and more recent evidence on this question. These authors find high currency risk premia in emerging markets, and show that country-specific risk factors such 
as per capita GNP, sovereign ratings and interest rate differentials are much more important than systematic portfolio risk factors in explaining the cross-country variation is risk premia. Our model explores one important country-specific risk factor, fiscal spending discretion in response to unanticipated seigniorage flows. Gavin and Perotti (1997) document that Latin American countries do indeed exhibit much more fiscal volatility than OECD countries.

Our paper is part of a large theoretical literature trying to explain nominal interest rate risk premia. These are generally decomposed into default risk premia and 'currency risk' premia. While there is a well-established and growing literature on interest rate default risk premia ${ }^{2}$, currency risk is a less straightforward notion. Engel (1992) and Stulz (1984) show that in flexible price monetary models monetary volatility per se will not give rise to a risk premium. Engel (1999), using the frameworks of Obstfeld and Rogoff (1998, 2000) and Devereux and Engel (1998), shows that sticky prices are required to generate a risk premium. Specifically, the expected correlation of the exchange rate with the marginal utility of consumption gives rise to a currency risk premium or discount, while volatility of the exchange rate per se unambiguously gives rise to a discount due to a Jensen's inequality term. However both of these terms are generally empirically small. Closest in spirit to the popular notion that currency risk gives rise to a significant positive risk premium is the literature on the Peso problem, see e.g. Obstfeld (1987), which holds that high risk premia can arise due to a very small risk of a very large devaluation under fixed exchange rates. However, this notion is less applicable to today's many emerging markets operating a flexible exchange rate regime. Our theory suggests an alternative explanation that does not depend on sticky prices but instead on a weak and very plausible assumption about fiscal policy. An important difference to the sticky price model is that in our environment the domestic nominal interest rate can be set by monetary policy independently of the path for the primary nominal anchor.

\footnotetext{
2 The early contributions include Eaton and Gersovitz (1981) and Aizenman (1989). More recent contributions include Kehoe and Perri (2001), Kletzer and Wright (2000) and Uribe (2001).
} 
The rest of the paper is organized as follows. Section II lays out the model for the benchmark case of fiscal spending neutrality. Section III discusses the case of fiscal nonneutrality. It contains the two main results. The first is a new, fiscal theory of currency risk premia, and the second a general equilibrium portfolio balance relationship which implies that sterilized intervention affects equilibrium allocations and prices. Section IV concludes. Mathematical details are presented in a number of appendices.

\section{THE BENCHMARK CASE: FISCAL NEUTRALITY AND UNCOVERED INTEREST PARITY}

Consider a small open endowment economy composed of a continuum of identical infinitely lived households and a government. Households can hold three types of non-state-contingent assets, domestic currency denominated money and bonds and foreign currency denominated bonds. Capital is perfectly mobile internationally. The nominal exchange rate $E_{t}$ floats. Aggregate exchange rate risk cannot be hedged through financial instruments. ${ }^{3}$ We will see that this may, but need not, imply that financial markets are incomplete. All goods are tradable and the international price level $P_{t}^{*}$ is normalized to one. Assuming purchasing power parity, domestic goods prices $P_{t}$ therefore satisfy $P_{t}=E_{t}$. Nominal variables are denoted by upper case letters and real variables in terms of tradable goods by lower case letters.

We use a continuous time stochastic monetary portfolio choice model to derive households' optimal consumption and portfolio decisions. ${ }^{4}$ In order to determine the

3 This requires that the risk of the domestic currency is too idiosyncratic to be internationally diversifiable, or that that market is too small relative to transactions costs. Both are plausible for emerging markets. Of course individual households can hedge domestically if there is heterogeneity among them. But what matters is that households as a whole cannot hedge their aggregate domestic currency exposure vis-a-vis their own government.

4 Useful surveys of the technical aspects of stochastic optimal control are contained in Chow (1979), Fleming and Rishel (1975), Malliaris and Brock (1982), Karatzas and Shreve (1991), and Duffie (1996). The seminal papers using this technique to analyze macroeconomic portfolio selection are Merton $(1969,1971)$ and Cox, Ingersoll and Ross (1985). Other contributions include Dumas and Uppal (2000), Grinols and Turnovsky (1994), and Stulz (1983, 1984, 1987, 1988). 
equilibrium portfolio share of domestic currency denominated bonds in a small open economy, we follow Grinols and Turnovsky (1994) in assuming that these bonds are held exclusively by domestic residents. This is not a restrictive assumption for many emerging markets, where the vast majority of claims by foreigners tends to be denominated in dollars. Figure 1 illustrates this for the case of Mexico.

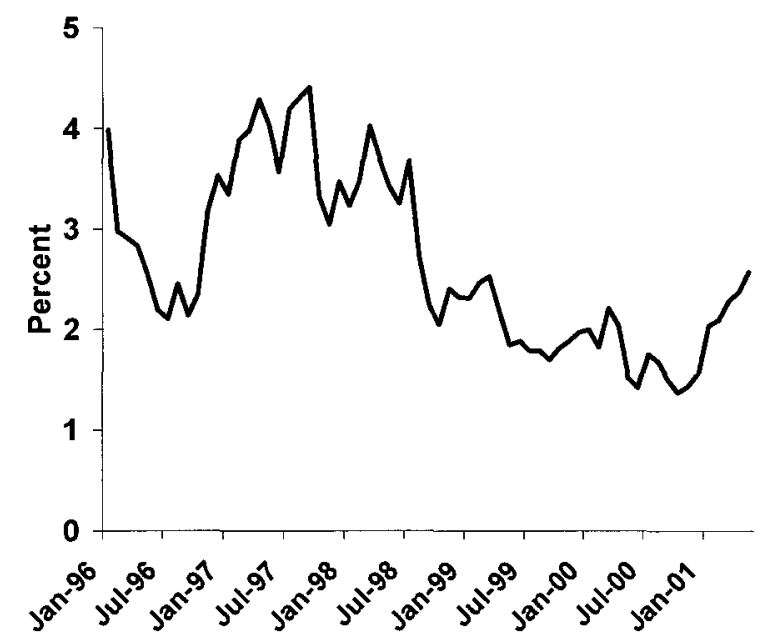

Figure 1: Mexico - Foreigners' Holdings of Peso Denominated Government Debt as $\%$ of Total Peso Denominated Government Debt (Source: Banco de Mexico)

The only source of uncertainty in this economy is the growth rate of the nominal money supply. We fix a probability space $(\Omega, \digamma, P)$. A stochastic process is a measurable function $\Omega \times[0, \infty): \mapsto \Re$. The value of a process $X$ at time $t$ is the random variable written as $X_{t}$. The nominal money supply follows a geometric Brownian motion with drift process $\mu_{t}$ and constant, exogenous diffusion $\sigma^{M}$ :

$$
\frac{d M_{t}}{M_{t}}=\mu_{t} d t+\sigma^{M} d B_{t},
$$

where $B_{t}$ is a one-dimensional Brownian motion. The tribe $\digamma_{t}^{B}$ includes every event based on the history of the Brownian motion up to time $t$. We complete the probability space by assigning probabilities to subsets of events with zero probability. We define $\digamma_{t}$ to be the tribe generated by the union of $\digamma_{t}^{B}$ and the null sets. This leads to the standard filtration 
$\digamma=\left\{\digamma_{t}: t \geq 0\right\}$. The nominal exchange rate process $E_{t}$ is endogenously determined as a function of the money supply process. It follows a geometric Brownian motion, with its drift process $\varepsilon_{t}$ and diffusion process $\sigma_{t}^{E}$ to be determined in equilibrium:

$$
\frac{d E_{t}}{E_{t}}=\varepsilon_{t} d t+\sigma_{t}^{E} d B_{t}
$$

We assume and later verify that the drift and diffusion are adapted processes satisfying $\int_{0}^{T}\left|\varepsilon_{t}\right| d t<\infty$ almost surely for each $T$ and $\int_{0}^{T}\left(\sigma_{t}^{E}\right)^{2} d t<\infty$ almost surely for each $T$. We note that $\sigma_{t}^{E}$ can in general be positive or negative.

\section{A. Households}

The representative household has time-separable logarithmic preferences over his lifetime stochastic path of tradable goods consumption $\left\{c_{t}\right\}_{t=0}^{\infty}$ :

$$
E_{0} \int_{0}^{\infty} e^{-\beta t} \ln \left(c_{t}\right) d t \quad, \quad 0<\beta<1,
$$

where $\beta$ is the rate of time preference. Logarithmic preferences are commonly assumed in the open economy asset pricing and portfolio choice literature for their analytical tractability, see e.g. Stulz $(1984,1987)$ and Zapatero (1995). Households are endowed with a deterministic sequence of tradables $\left\{y_{t}\right\}_{t=0}^{\infty}$. We assume that $y_{t}=y \forall t$. Households can invest in three non-contingent assets. High-powered money $m_{t}=\frac{M_{t}}{E_{t}}$ pays a zero nominal return, domestic currency denominated government bonds $q_{t}=\frac{Q_{t}}{E_{t}}$ pay a nominal interest rate $i_{t}^{q}$, and foreign currency denominated international bonds $\tilde{b}_{t}$ pay the real international interest rate $r_{t}$. We assume that $r_{t}=r \forall t$. Households finance their consumption from the return on their portfolio of assets and their endowment income. International tradable wealth is defined as the sum of international bond holdings and the present discounted value of tradables endowments: ${ }^{5}$

$$
b_{t}=\tilde{b}_{t}+\frac{y}{r}
$$

\footnotetext{
5 Tradables endowments could therefore be dropped from the model without loss of generality. We chose to retain them in order to follow the convention in much of the small open economy literature.
} 
Total private wealth therefore equals $a_{t}=b_{t}+q_{t}+m_{t}$. Portfolio shares of money and domestic bonds will be denoted by $n_{t}^{m}=\frac{m_{t}}{a_{t}}$ and $n_{t}^{q}=\frac{q_{t}}{a_{t}}$. Finally, households are subject to a lump-sum tax $d T_{t}$ levied as a proportion of wealth and following an Itô process with adapted drift process $\tau_{t}$ and diffusion process $\sigma_{t}^{T}$ :

$$
\frac{d T_{t}}{a_{t}}=\tau_{t} d t+\sigma_{t}^{T} d B_{t}
$$

The drift and diffusion terms will be determined in equilibrium from a balanced budget requirement for the government. We assume that $\int_{0}^{T}\left|\tau_{t}\right| d t<\infty$ almost surely for each $T$ and $\int_{0}^{T}\left(\sigma_{t}^{T}\right)^{2} d t<\infty$ almost surely for each $T$, and will later verify that this is satisfied in equilibrium. The household budget constraint is given by

$$
d a_{t}=a_{t}\left[n_{t}^{m} d r_{t}^{m}+n_{t}^{q} d r_{t}^{q}+\left(1-n_{t}^{m}-n_{t}^{q}\right) d r_{t}^{b}\right]-c_{t} d t-a_{t}\left[\tau_{t} d t+\sigma_{t}^{T} d B_{t}\right],
$$

where $r_{t}^{i}$ is the real rate of return on asset $i$. Many monetary portfolio choice models introduce money into the utility function separably because this preserves the separability between portfolio and savings decisions found in Merton $(1969,1971)$. However, as pointed out by Feenstra (1986), without a positive cross partial between money and consumption the existence of money cannot be rationalized through transactions cost savings. We therefore use a cash constraint instead, and show that it is nevertheless possible to obtain very elegant analytical solutions. Specifically, consumers are required to hold real money balances equal to a fixed multiple $\alpha$ of their consumption expenditures:

$$
\alpha c_{t}=m_{t}=n_{t}^{m} a_{t}
$$

The now very common treatment of the cash-in-advance constraint in Lucas (1990) has two aspects, a cash requirement aspect and an in-advance aspect. Our own treatment goes back to the earlier Lucas (1982), which uses only the cash requirement aspect. This is due to the difficulty of implementing the in-advance timing conventions in a continuous-time framework. In the continuous time stochastic finance literature, Bakshi and Chen (1997) have used the same device. Finally, note that equation (6) could also be obtained as an 
optimality condition by assuming Leontief preferences over consumption and real balances, $\int_{0}^{\infty} e^{-\beta t} \ln \left(\min \left(c_{t}, m_{t} / \alpha\right)\right) d t$

Using Itô's lemma we can derive the real returns in terms of tradable goods on money, domestic bonds and foreign bonds (see Appendix I):

$$
\begin{gathered}
d r_{t}^{m}=\left(-\varepsilon_{t}+\left(\sigma_{t}^{E}\right)^{2}\right) d t-\sigma_{t}^{E} d B_{t} \\
d r_{t}^{q}=\left(i_{t}^{q}-\varepsilon_{t}+\left(\sigma_{t}^{E}\right)^{2}\right) d t-\sigma_{t}^{E} d B_{t} \\
d r_{t}^{b}=r d t .
\end{gathered}
$$

Note that the exchange rate affects returns in two ways. First, depreciation $\sigma_{t}^{E} d B_{t}>0$ reduces the ex-post real value of domestic assets in terms of tradables. Second, by Jensen's inequality, larger exchange rate volatility $\left(\sigma_{t}^{E}\right)^{2}$ increases their ex-ante real return.

The household's portfolio problem is to maximize present discounted lifetime utility by the appropriate portfolio choice $\left\{n_{t}^{m}, n_{t}^{q}\right\}_{t=0}^{\infty}$ :

$$
\begin{aligned}
\max _{\left\{n_{t}^{m}, n_{t}^{q}\right\}_{t=0}^{\infty}}\left\{E_{0} \int_{0}^{\infty} e^{-\beta t} \ln \left(n_{t}^{m} a_{t} / \alpha\right) d t\right\} \text { s.t. } \\
d a_{t}=a_{t}\left\{\left(r-\tau_{t}\right) d t+n_{t}^{q}\left[\left(i_{t}^{q}+\left(\sigma_{t}^{E}\right)^{2}-r-\varepsilon_{t}\right) d t-\sigma_{t}^{E} d B_{t}\right]\right. \\
\left.+n_{t}^{m}\left[\left(\left(\sigma_{t}^{E}\right)^{2}-r-\varepsilon_{t}-\frac{1}{\alpha}\right) d t-\sigma_{t}^{E} d B_{t}\right]-\sigma_{t}^{T} d B_{t}\right\} .
\end{aligned}
$$

We will solve this optimal portfolio problem recursively using a continuous time Bellman equation, as in Merton $(1969,1971)$. Let $V\left(a_{t}, t\right)=e^{-\beta t} J\left(a_{t}, t\right) \in C^{2}$ be a solution of the Hamilton-Jacobi-Bellman equation of stochastic optimal control. Let $\dot{J}=\partial J\left(a_{t}, t\right) / \partial t$. Then the Hamilton-Jacobi-Bellman equation is

$$
\begin{aligned}
\beta J-\dot{J}= & \sup _{n_{m_{t}}, n_{q_{t}}}\left\{\ln \left(n_{t}^{m} a_{t} / \alpha\right)+J_{a} a_{t}\left[\left(r-\tau_{t}\right)\right.\right. \\
& \left.+n_{t}^{m}\left(\left(\sigma_{t}^{E}\right)^{2}-r-\varepsilon_{t}-\frac{1}{\alpha}\right)+n_{t}^{q}\left(i_{t}^{q}+\left(\sigma_{t}^{E}\right)^{2}-r-\varepsilon_{t}\right)\right] \\
& \left.+\frac{1}{2} J_{a a} a_{t}^{2}\left[\left(\sigma_{t}^{E}\right)^{2}\left(\left(n_{t}^{m}\right)^{2}+\left(n_{t}^{q}\right)^{2}+2 n_{t}^{m} n_{t}^{q}\right)+\left(\sigma_{t}^{T}\right)^{2}+2 \sigma_{t}^{E} \sigma_{t}^{T}\left(n_{t}^{m}+n_{t}^{q}\right)\right]\right\}
\end{aligned}
$$


with boundary condition

$$
\lim _{\tau \rightarrow \infty} E_{0}\left[e^{-\beta \tau}\left|J\left(a_{\tau}, \tau\right)\right|\right]=0 .
$$

Optimality for $n_{t}^{q}$ requires

$$
n_{t}^{q}+n_{t}^{m}=\left(\frac{-J_{a}}{J_{a a} a_{t}}\right) \frac{\left(i_{t}^{q}+\left(\sigma_{t}^{E}\right)^{2}-r-\varepsilon_{t}\right)}{\left(\sigma_{t}^{E}\right)^{2}}-\frac{\sigma_{t}^{T}}{\sigma_{t}^{E}},
$$

and the first order condition for $n_{t}^{m}$ is:

$$
\left(n_{t}^{m} a_{t} / \alpha\right)^{-1}=J_{a}\left(1+\alpha i_{t}^{q}\right) .
$$

The marginal utility of consumption equals the marginal utility of wealth $J_{a}$ times the effective price of consumption, where the latter varies with the opportunity cost of holding money balances for transactions purposes. A closed form solution for $J$, which is required to get an explicit expression, will be derived in subsection $\mathrm{C}$ following the definition of equilibrium.

\section{B. Government}

Monetary policy is characterized by the money supply process (1) and by

$$
\begin{gathered}
\frac{Q_{t}}{M_{t}}=\psi, \\
M_{0-}(1+\psi)\left(\frac{1}{E_{0-}}-\frac{1}{E_{0}}\right)=\tilde{b}_{0}-\tilde{b}_{0-}=h_{0-}-h_{0} .
\end{gathered}
$$

The government indirectly pursues an inflation objective through the control of the growth rate $\mu_{t}$ of the nominal base money supply $M_{t}$ in (1). The diffusion process $\sigma^{M}$ however is assumed to be constant and exogenous to the government. Under these assumptions the regularity conditions $\int_{0}^{T}\left|\mu_{t}\right| d t<\infty$ almost surely for each $T$ and $\int_{0}^{T}\left(\sigma_{t}^{M}\right)^{2} d t<\infty$ almost surely for each $T$ are trivially satisfied. Also, being an Itô process, $M_{t}$ is continuous, which ensures exchange rate determinacy.

The central bank is assumed to be the sole issuer of domestic currency denominated public debt. Rule (14) follows Grinols and Turnovsky (1994) in stating that it issues such 
debt in a constant proportion $\psi$ to the base money supply and thereby determines the portfolio share of domestic bonds from their supply side. The importance of this rule will become clearer in our discussion of households' equilibrium portfolio choices in subsection C.

Discrete unanticipated policy changes will generally result in discontinuous jumps of the nominal exchange rate on impact ${ }^{6}$, denoted $E_{0}-E_{0-}$. Here $0_{-}$stands for the instant before the announcement of a new policy at time 0 . At such points the government is assumed to fully redistribute the associated net seigniorage revenue through a one-off transfer of foreign bonds, as stated in equation (15). This ensures that private financial wealth remains unchanged upon the impact of a new policy.

The relationship between fiscal policy rules and the possibility of more general rules than (14) for domestic currency denominated public debt will play a key role in this paper. In this section fiscal policy consists of net lump-sum taxes which ensure that budget balance is maintained at all times while government spending is zero. Net taxes are proportional to wealth and follow the rule (4). Let $h_{t}$ be the government's stock of real net foreign assets, or foreign exchange reserves. We have:

Assumption 1: The government redistributes all net revenues on its portfolio of assets and liabilities to households through its net lump-sum taxes.

The government's budget constraint is therefore

$$
a_{t} \tau_{t} d t+a_{t} \sigma_{t}^{T} d B_{t}+h_{t} d r_{t}^{b}=m_{t} d r_{t}^{m}+q_{t} d r_{t}^{q} .
$$

Assumption 1 together with policies (14) and (15) imply that the government's net wealth $W_{t}=h_{t}-m_{t}-q_{t}$ does not change over time:

$$
d W_{t}=d h_{t}-d m_{t}-d q_{t}=a_{t} \tau_{t} d t+a_{t} \sigma_{t}^{T} d B_{t}+h_{t} d r_{t}^{b}-m_{t} d r_{t}^{m}-q_{t} d r_{t}^{q}=0
$$

\footnotetext{
$6 \quad$ Subsequent discontinuous exchange rate jumps are ruled out by arbitrage.
} 
Therefore we have $d h_{t}=d m_{t}+d q_{t}$. For simplicity we also assume the initial condition $W_{0-}=0$, or

$$
h_{0-}=m_{0-}+q_{0-},
$$

which implies that

$$
h_{t}=m_{t}+q_{t} \quad \forall t .
$$

This formulation treats government issued and central bank issued domestic currency bonds as perfect substitutes, so that $q_{t}$ could represent either debt class. Condition (18) therefore states that the consolidated government's net domestic currency denominated liabilities are fully backed by net foreign securities.? It should also be pointed out that, given perfect international capital mobility, the assumption of instantaneous redistribution in (16) is not restrictive. It is equivalent to redistribution over households' infinite lifetime combined with instantaneous capitalization by households of the expected redistribution stream. Our treatment is notationally more convenient.

To determine the drift $\tau_{t}$ and diffusion $\sigma_{t}^{T}$ of the tax process $d T_{t}$ we equate terms in (16) using (7) - (9) and (18) to obtain the following:

$$
\begin{gathered}
\tau_{t}=n_{t}^{m}\left(\left(\sigma_{t}^{E}\right)^{2}-r-\varepsilon_{t}\right)+n_{t}^{q}\left(i_{t}^{q}+\left(\sigma_{t}^{E}\right)^{2}-r-\varepsilon_{t}\right), \\
\sigma_{t}^{T}=-\left(n_{t}^{m}+n_{t}^{q}\right) \sigma_{t}^{E} .
\end{gathered}
$$

\section{Equilibrium and Balance of Payments}

We define a government policy as an initial net compensation $h_{0-}-h_{0}$ and a list of stochastic processes ${ }^{8}\left\{\mu_{t}, \psi_{t}, \tau_{t}, \sigma_{t}^{T}\right\}_{t=0}^{\infty}$ such that, given exogenous constants $r, y, P^{*}$ and $\sigma^{M}$, initial conditions $a_{0_{-}}, h_{0-}, M_{0_{-}}, Q_{0-}$ and $E_{0-}$, an initial exchange rate jump $E_{0}-E_{0-}$, and a list of stochastic processes $\left\{\varepsilon_{t}, \sigma_{t}^{E}, d B_{t}, i_{t}^{q}, a_{t}\right\}_{t=0}^{\infty}$, the balanced budget conditions (19)

7 Note that $q_{t}$ could be negative and represent government claims on the private sector. In that case $h_{t}$ could also be negative.

8 In all policy experiments we will assume for simplicity that $\left\{\mu_{t}, \lambda_{t}\right\}_{t=0}^{\infty}$ are deterministic sequences. 
and (20) and monetary policy rules (1), (14) and (15) hold at all times. Then equilibrium is defined as follows:

Definition 1: For given $r, y, P^{*}$ and $\sigma^{M}$, an equilibrium is a set of initial conditions $a_{0-}, h_{0-}, M_{0-}, Q_{0-}$ and $E_{0--}$, an exogenous stochastic process $\left\{d B_{t}\right\}_{t=0}^{\infty}$, an allocation consisting of stochastic processes $\left\{c_{t}, a_{t}, h_{t}, Q_{t}, M_{t}\right\}_{t=0}^{\infty}$, a price system consisting of an initial exchange rate jump $E_{0}-E_{0^{-}}$and stochastic processes $\left\{\varepsilon_{t}, \sigma_{t}^{E}, i_{t}^{q}\right\}_{t=0}^{\infty}$, and a government policy such that given the initial conditions, the exogenous stochastic process, the government policy and the price system, the allocation solves households' problem of maximizing (3) subject to (5) and (6), resulting in optimality conditions (12) and (13).

The condition $h_{t}=m_{t}+q_{t} \forall t$ ensures that $a_{t}=b_{t}+h_{t} \forall t$, i.e. real tradable private assets at any point are equal to the economy's net foreign assets. Then the current account can be derived by consolidating households' and the government's budget constraint (5) and (16). Because all risk is between the government and the domestic private sector, the current account does not contain stochastic terms: ${ }^{9}$

$$
d a_{t}=r a_{t} d t-c_{t} d t
$$

Households' lifetime budget constraint is identical to the economy's aggregate budget constraint:

$$
\int_{0}^{\infty} c_{t} e^{-r t} d t=a_{0}
$$

We are now ready to derive a closed form expression for the household value function $V\left(a_{t}, t\right)=e^{-\beta t} J\left(a_{t}, t\right)$. The solution proceeds by first substituting (12), (13), (19) and (20), which contain the terms $J_{a}$ and $J_{a a}$, back into the Hamilton-Jacobi-Bellman equation. That equation is then solved for $J$ by way of a conjecture. Given our specification of the utility function a good conjecture is

$$
V\left(a_{t}, t\right)=e^{-\beta t} J\left(a_{t}, t\right)=e^{-\beta t} X\left[\ln \left(a_{t}\right)+\ln (Y(t))\right],
$$

9 The current account can also be written in a more familiar form by letting $F_{t}=h_{t}+\tilde{b}_{t}$ :

$$
d F_{t}=r F_{t} d t+y d t-c_{t} d t
$$


where $X$ and $Y(t)$ are to be determined in the process of verifying the conjecture. We allow for $Y(t)$ to be a function of time. To understand this note that the value function represents the present discounted value of future consumption streams. First-order condition (13) together with conjecture (23) implies that consumption at any given point in time is proportional to $a_{t}$ and decreasing in $i_{t}^{q}$. We will consider policy experiments involving anticipated time-varying rates of money growth. This will in general give rise to a time-varying domestic interest rate $i_{t}^{q}$ and therefore to a time-varying rate of consumption out of current assets. In the transition to steady state the value function is therefore a function of time.

In Appendix II we show that $X=\beta^{-1}$, which yields equilibrium portfolio shares of

$$
n_{t}^{m}=\frac{\alpha \beta}{\left(1+\alpha i_{t}^{q}\right)} \quad, \quad n_{t}^{q}=\psi n_{t}^{m},
$$

and an optimal consumption policy function of

$$
c_{t}=a_{t} \frac{\beta}{\left(1+\alpha i_{t}^{q}\right)} .
$$

Equilibrium exchange rate volatility is shown in Appendix II to equal

$$
\sigma_{t}^{E}=\sigma^{M} \forall t .
$$

This yields the following relationship between domestic and foreign interest rates:

$$
i_{t}^{q}=r+\varepsilon_{t}-\left(\sigma^{M}\right)^{2} .
$$

This is a version of the uncovered interest parity condition, the only difference to the standard version being the Jensen's inequality term $\left(\sigma^{M}\right)^{2}$. Domestic and foreign bonds are therefore perfect substitutes, despite the presence of exchange rate risk and despite the absence of financial markets to hedge against such risk. The reason is that markets are in fact complete because the tax policy (20) fully insures agents against exchange rate risk.

Equation (27) also shows that an interest rate target is equivalent to an exchange rate target in the current setting. Because an exchange rate target would have to make the money supply endogenous it is incompatible with the money growth rate rule (1). Therefore the 
nominal interest rate is endogenous and cannot be set by policy. This, together with the fact that perfect asset substitutability implies an indeterminate private portfolio demand for domestic currency denominated bonds, shows why policy rule (14) had to take the form of a quantity supply rule anchored to the nominal money supply. ${ }^{10}$

For ease of exposition of our results, we now rule out inessential dynamics by imposing a condition on $\beta$ that ensures a flat steady state consumption path. ${ }^{11}$ We denote steady state quantities and prices by a bar over the respective variables. Let $\bar{\mu}$ be the steady state growth rate of money determined by government policy. From (21) and (25) a flat consumption path requires $\bar{c}=r \bar{a}$. Then from (6) steady state exchange rate depreciation must satisfy $\bar{\varepsilon}=\bar{\mu}$, and therefore by (27) we have $\bar{\imath}^{q}=r+\bar{\mu}-\left(\sigma^{M}\right)^{2}$. By (25) this implies that $\beta$ must satisfy

$$
\beta=r\left(1+\alpha \bar{\imath}^{q}\right)
$$

Therefore the optimal portfolio fractions for money and bonds in steady state are $\bar{n}^{m}=\alpha r$ and $\bar{n}^{q}=\alpha \psi r$. Appendix II also derives the equilibrium differential equation for $i_{t}^{q}$. This equation is shown to be unstable around the steady state, which establishes uniqueness of perfect foresight equilibria. We have:

$$
i_{t}^{q}=\frac{1+\alpha i_{t}^{q}}{\alpha}\left(i_{t}^{q}+\left(\sigma^{M}\right)^{2}-\mu_{t}\right)-\frac{\beta}{\alpha} .
$$

We finally verify that the regularity conditions posited earlier for $\varepsilon_{t}, \sigma_{t}^{E}, \tau_{t}$ and $\sigma_{t}^{T}$ hold. The sequence $\left\{\mu_{t}\right\}_{t=0}^{\infty}$ will be assumed to be bounded by our specification of monetary policy in subsection D. The explosive dynamics of $i_{t}^{q}$ in (29), combined with (27), imply that $i_{t}^{q}$ and $\varepsilon_{t}$ are unstable around the steady state. The equilibrium paths $\left\{i_{t}^{q}, \varepsilon_{t}\right\}_{t=0}^{\infty}$ are therefore unique and bounded. Therefore they satisfy the conditions $\int_{0}^{T}\left|\varepsilon_{t}\right| d t<\infty$ almost surely for each $T$ and $\int_{0}^{T}\left|i_{t}^{q}\right| d t<\infty$ almost surely for each $T$. The process $\left\{\sigma_{t}^{E}\right\}_{t=0}^{\infty}$ is constant at $\sigma^{M}$ in equilibrium, and hence $\int_{0}^{T}\left(\sigma_{t}^{E}\right)^{2} d t<\infty$ almost surely for each $T$ holds trivially.

\footnotetext{
10 A determinate portfolio share is needed in Appendix II to solve for the closed form value function.

11 This condition is not strictly required because the transversality condition can be shown to hold without it for a range of parameter values.
} 
The previous results, by (24), (19) and (20), imply that $\tau_{t}$ and $\sigma_{t}^{T}$ satisfy $\int_{0}^{T}\left|\tau_{t}\right| d t<\infty$ almost surely for each $T$ and $\int_{0}^{T}\left(\sigma_{t}^{T}\right)^{2} d t<\infty$ almost surely for each $T$.

\section{Monetary Policy}

In discussing monetary policy we will distinguish between once-and-for-all unanticipated stock operations on the one hand and policies with anticipated time-varying paths of interest rates or money growth rates on the other hand. Stock operations in turn fall into three categories. An unsterilized foreign exchange intervention is a sale or purchase of foreign exchange reserves $h$ in exchange for domestic money $M$. An open market operation is a sale or purchase of domestic currency bonds $Q$ in exchange for domestic money $M$. Such operations can be used to 'sterilize' the effect of an unsterilized intervention on the money stock. A fully sterilized foreign exchange intervention is therefore a sale or purchase of domestic currency bonds $Q$ in exchange for foreign currency bonds $h$. For all stock operations we assume that private asset holders are fully compensated by the government for the effects of unanticipated initial jumps in the nominal exchange rate on the real value of their assets. Compensation takes the form of foreign bond transfers.

\section{a. Stock Operations}

Unsterilized intervention can be effected through a once-and-for-all change in $\psi$. Consider a monetary contraction through a sale of foreign exchange reserves. Given full compensation this has no effect on real wealth. Differentiating the optimality condition (25) and the cash constraint (6) shows that the only stable solution is for exchange rate depreciation and therefore the nominal interest rate to stay at its unchanged steady state value. By the cash constraint the nominal exchange rate therefore appreciates in proportion to the change in nominal money balances. All real allocations are unaffected. An open market operation that fully sterilizes the previous operation by returning $M$ to its old value requires another one-off change in $\psi$. By the same argument as above, the nominal exchange 
rate simply returns to its old value, the nominal interest rate does not change, and all real allocations remain the same. Sterilized intervention therefore, being simply the sum of the previous two operations, has no effects at all because it does not affect the nominal money stock. It simply represents a contraction or expansion of both the asset and liability side of the central bank balance sheet, with an offsetting switch between domestic currency and foreign currency bonds in private portfolios. This is irrelevant because these asset classes are perfect substitutes. For the same reason open market operations and unsterilized foreign exchange interventions that involve the same change in $M$ have the exact same effect and are in fact indistinguishable operations.

\section{b. Money Growth Policies}

Given the foregoing results, it is clear that the effects of variations in $\mu_{t}$ are very similar to those obtained in perfect foresight models featuring uncovered interest parity. Consider as a simple example an unanticipated temporary step reduction in $\mu_{t}$ :

$$
\mu_{t}=\mu_{L} \text { for } t \in[0, T) \quad, \quad \mu_{t}=\bar{\mu}=\mu_{H}>\mu_{L} \text { for } t \geq T
$$

Figure 2 illustrates.
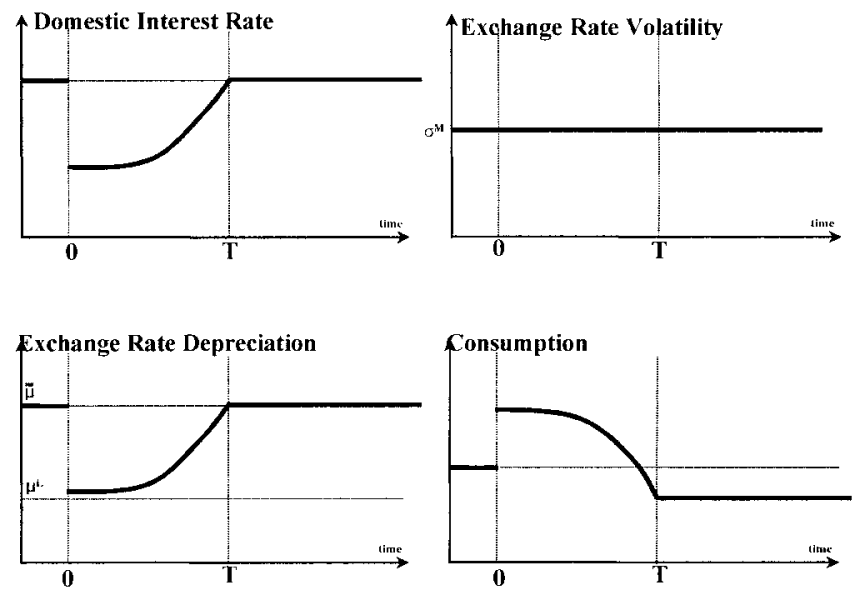

Figure 2 : Temporary Money Growth Reduction under Fiscal Neutrality 
The policy causes an instantaneous downward jump in the drift of the exchange rate $\varepsilon_{t}$ at time 0 , followed by a slow convergence to $\mu_{H}$ by time $T$. The path of the domestic nominal interest rate $i_{t}^{q}$ mirrors that of $\varepsilon_{t}$ by (27). This is accompanied from (25) by an initial upward jump in consumption, followed by a declining consumption path. The new steady state level of consumption is permanently lower because of the period of current account deficits, see (22). Note finally that a permanent reduction of $\mu_{t}$ would cause an immediate and equal reduction of $\varepsilon_{t}$, without any real effects.

\section{FISCAL NONNEUTRALITY AND PORTFOLIO BALANCE}

In this section we develop the main results of the paper. We highlight the importance of nonneutral fiscal policy rules by contrasting the results with those of Section II. In particular, we assume that the government only uses net lump-sum taxes to redistribute the nonstochastic component of net income flows on its portfolio of assets and liabilities. Its real ex-ante expenditure budget is fixed at zero in real terms, but all stochastic seigniorage shocks lead to real spending adjustments. In particular, when exchange rate depreciation generates additional seigniorage income the government spends the proceeds on goods which do not enter household utility. And when the exchange rate appreciates the government reduces spending to make extra goods available to households. The assumption of net zero spending in the absence of exchange rate shocks is simply a convenient normalization.

This specification of fiscal policy is intuitively plausible for many emerging markets. Also, it is precisely for these economies that Bansal and Dahlquist (2000) find large positive currency risk premia, and we will now show that a fiscal spending nonneutrality is one way to explain such premia. 


\section{A. Government}

The basic model specification is the same as in Section II, except for a different fiscal policy rule and resulting changes in the set of possible monetary policies.

We begin with monetary policy. A target path for money growth $\left\{\mu_{t}\right\}_{t=0}^{\infty}$ enters the money evolution equation (1) as before. The domestic debt quantity rule (14) is however replaced, based on the conjecture that we will find a determinate portfolio demand share for domestic currency bonds $n_{t}^{q}$. In that case once-and-for-all changes in the market nominal interest rate $i^{q}$ can be effected through once-and-for-all changes in the nominal bond supply $Q$, or equivalently through the setting of an exogenous policy interest rate $\hat{\imath}_{t}^{q}$. We will consider 'Stock Operations' in subsection D.a. below. But we also want to consider time-varying target paths of monetary policy variables other than $\left\{\mu_{t}\right\}_{t=0}^{\infty}$, and here it is most intuitive to think about an interest rate target path $\left\{\hat{\imath}_{t}^{q}\right\}_{t=0}^{\infty}:{ }^{12}$

$$
i_{t}^{q}=\hat{\imath}_{t}^{q} \quad \forall t
$$

It will be verified below that the portfolio demand share $n_{t}^{q}$ is indeed determinate, and that therefore policy (31) is feasible in equilibrium. The specific interest rate policy we will analyze is similar to (30) in that it has exactly one anticipated jump at a future time $T$ :

$$
\hat{\imath}_{t}^{q}=\hat{\imath}_{H}^{q} \text { for } t \in[0, T) \quad, \quad \hat{\imath}_{t}^{q}=\bar{\imath}^{q}=\hat{\imath}_{L}^{q}<\hat{\imath}_{H}^{q} \text { for } t \geq T
$$

Finally, the compensation rule (15) must also change to reflect the fact that money and domestic bonds are no longer issued in fixed proportions:

$$
\left(M_{0-}+Q_{0-}\right)\left(\frac{1}{E_{0-}}-\frac{1}{E_{0}}\right)=\tilde{b}_{0}-\tilde{b}_{0-}=h_{0-}-h_{0} .
$$

Next we consider fiscal policy. The government is again required to balance its budget period by period, but the budget now has an endogenous spending component $d G_{t}$ that depends on stochastic seigniorage flows. Consequently households no longer face tax rule

\footnotetext{
12 This implies a contingent time path for the nominal bond stock $Q$. Fixing a $Q$-path would imply a contingent time path for the nominal interest rate $i^{q}$.
} 
(4) but instead a rule without a stochastic component:

$$
\frac{d T_{t}}{a_{t}}=\tau_{t} d t
$$

Assumption 1 is replaced as follows:

Assumption 2: The government redistributes all nonstochastic net revenues on its portfolio to households through net lump-sum taxes. It changes its spending on goods in response to unanticipated net revenue shocks.

The government budget constraint is therefore

$$
a_{t} \tau_{t} d t+h_{t} d r_{t}^{b}=q_{t} d r_{t}^{q}+m_{t} d r_{t}^{m}+d G_{t}
$$

We continue to assume the initial condition (17). Assumption 2 together with policy (33) again means that $d h_{t}=d m_{t}+d q_{t}$, which implies the central bank balance sheet equality (18). To determine the drift of the tax process $\tau_{t}$ and the endogenous spending term $d G_{t}$ we equate terms in (35) using (34), (7) - (9), (18), and Assumption 2. We obtain the following:

$$
\begin{gathered}
\tau_{t}=n_{t}^{m}\left(-r-\varepsilon_{t}\right)+n_{t}^{q}\left(i_{t}^{q}-r-\varepsilon_{t}\right), \\
d G_{t}=a_{t}\left(n_{t}^{m}+n_{t}^{q}\right)\left[-\left(\sigma_{t}^{E}\right)^{2} d t+\sigma_{t}^{E} d B_{t}\right] .
\end{gathered}
$$

Note that if agents hold positive amounts of domestic assets $\left(n_{t}^{m}+n_{t}^{q}\right)>0$, expected government spending is negative and decreasing in the volatility of exchange rates: ${ }^{13}$

$$
\frac{E\left(d G_{t}\right)}{d t}=-\left(\sigma_{t}^{E}\right)^{2} a_{t}\left(n_{t}^{m}+n_{t}^{q}\right)
$$

The assumption that stochastic seigniorage flows are spent instantaneously is again only for notational convenience. Deferred net spending would be capitalized at the real international interest rate by households with perfect access to international capital markets, leaving equilibrium allocations unchanged.

\footnotetext{
13 Expected steady state spending could be renormalized to zero by introducing an autonomous spending component equal to $\left(E\left(d G_{t}\right) / d t\right)_{s s}$, where the subscript $s s$ stands for steady state.
} 


\section{B. Households}

With tax rule (34) the household budget constraint looks as follows:

$$
d a_{t}=a_{t}\left[n_{t}^{m} d r_{t}^{m}+n_{t}^{q} d r_{t}^{q}+\left(1-n_{t}^{q}-n_{t}^{m}\right) d r_{t}^{b}\right]-c_{t} d t-a_{t} \tau_{t} d t .
$$

We can immediately proceed to the new Hamilton-Jacobi-Bellman equation, where the only difference is the absence of the tax diffusion component:

$$
\begin{aligned}
\beta J-\dot{J}= & \sup _{n_{t}^{m}, n_{t}^{q}}\left\{\ln \left(n_{t}^{m} a_{t} / \alpha\right)+J_{a} a_{t}\left[\left(r-\tau_{t}\right)\right.\right. \\
& \left.+n_{t}^{q}\left(i_{t}^{q}+\left(\sigma_{t}^{E}\right)^{2}-r-\varepsilon_{t}\right)+n_{t}^{m}\left(\left(\sigma_{t}^{E}\right)^{2}-r-\varepsilon_{t}-\frac{1}{\alpha}\right)\right] \\
& \left.\left.+\frac{1}{2} J_{a a} a_{t}^{2}\left(\sigma_{t}^{E}\right)^{2}\left[\left(n_{t}^{m}\right)^{2}+\left(n_{t}^{q}\right)^{2}+2 n_{t}^{m} n_{t}^{q}\right)\right]\right\},
\end{aligned}
$$

with unchanged boundary condition (11). Optimality for $n_{t}^{q}$ requires:

$$
n_{t}^{q}+n_{t}^{m}=\left(\frac{-J_{a}}{J_{a a} a_{t}}\right) \frac{\left(i_{t}^{q}+\left(\sigma_{t}^{E}\right)^{2}-r-\varepsilon_{t}\right)}{\left(\sigma_{t}^{E}\right)^{2}} .
$$

In this economy the government has to pay a risk-adjusted premium on its interest rate, $i_{t}^{q}+\left(\sigma_{t}^{E}\right)^{2}-r-\varepsilon_{t}>0$, to persuade households to hold a positive amount $\left(n_{t}^{q}+n_{t}^{m}\right)>0$ of these assets. ${ }^{14}$ The reason is that fiscal policy generates risk for holders of domestic currency assets, but not of foreign currency assets. Finally, the first order condition for $n_{t}^{m}$ has the same form as in Section 2, see (13): ${ }^{15}$

$$
\left(n_{t}^{m} a_{t} / \alpha\right)^{-1}=J_{a}\left(1+\alpha i_{t}^{q}\right)
$$

\section{Equilibrium and Balance of Payments}

A government policy is now defined as an initial net compensation $h_{0-}-h_{0}$ and a list of stochastic processes $\left\{\mu_{t}, \hat{\imath}_{t}^{q}, \tau_{t}, d G_{t}\right\}_{t=0}^{\infty}$ such that, given exogenous constants $r, y^{*}, P^{*}$ and $\sigma^{M}$, initial conditions $a_{0_{-}}, h_{0_{-}}, M_{0_{-}}, Q_{0_{-}}$and $E_{0_{-}}$, an initial exchange rate jump $E_{0}-E_{0-}$, and a list of stochastic processes $\left\{\varepsilon_{t}, \sigma_{t}^{E}, d B_{t}, i_{t}^{q}, a_{t}, Q_{t}, M_{t}\right\}_{t=0}^{\infty}$, the balanced

\footnotetext{
14 Provided of course that, as will be proved below, the value function is strictly concave in wealth.

15 The condition need not be identical to (13) because $J_{a}$ may differ.
} 
budget conditions (36) and (37) and monetary policy rules (1), (31) and (33) hold at all times. Equilibrium is defined as follows:

Definition 2: For given $r, y^{*}, P^{*}$ and $\sigma^{M}$, an equilibrium is a set of initial conditions $a_{0-}, h_{0-}, M_{0_{-}}, Q_{0_{-}}$and $E_{0-}$, an exogenous stochastic process $\left\{d B_{t}\right\}_{t=0}^{\infty}$, an allocation consisting of stochastic processes $\left\{c_{t}, a_{t}, Q_{t}, M_{t}\right\}_{t=0}^{\infty}$, a price system consisting of an initial exchange rate jump $E_{0}-E_{0}$ - and stochastic processes $\left\{\varepsilon_{t}, \sigma_{t}^{E}, i_{t}^{q}\right\}_{t=0}^{\infty}$, and a government policy such that, given the initial conditions, the exogenous stochastic process, the government policy and the price system, the allocation solves households' problem of maximizing (3) subject to (39) and (6), resulting in conditions (41) and (42).

By consolidating households' and the government's budget constraint (39) and (35), and using (37), (41) and (18), the current account equation can be derived. It now contains a stochastic term because real fiscal spending depends on the realization of money shocks:

$$
\begin{aligned}
d a_{t} & =r a_{t} d t-c_{t} d t-d G_{t} \\
& =r a_{t} d t-c_{t} d t-a_{t}\left(\frac{-J_{a}}{J_{a a} a_{t}}\right) \frac{\left(i_{t}^{q}+\left(\sigma_{t}^{E}\right)^{2}-r-\varepsilon_{t}\right)}{\left(\sigma_{t}^{E}\right)^{2}}\left[-\left(\sigma_{t}^{E}\right)^{2} d t+\sigma_{t}^{E} d B_{t}\right]
\end{aligned}
$$

The economy's aggregate budget constraint becomes

$$
E_{0} \int_{0}^{\infty}\left(c_{t} e^{-r t} d t+d G_{t} e^{-r t}\right)=a_{0}
$$

Our conjecture for the functional form of the value function departs slightly from (23):

$$
\begin{aligned}
V\left(a_{t}, t\right) & =e^{-\beta t} J\left(a_{t}, t\right) \\
& \left.=e^{-\beta t} X\left[\ln \left(a_{t}\right)+\ln \left(Y\left(T_{-}\right)\right)+e^{-\beta(T-t)}\left\{\ln (Y(T))-\ln \left(Y\left(T_{-}\right)\right)\right\}\right], t \leq T_{45}\right) \\
& e^{-\beta t} X\left[\ln \left(a_{t}\right)+\ln (Y(T))\right] \quad, t>T
\end{aligned}
$$

The logic for the inclusion of a time-dependent term $Y(t)$ is the same as in our discussion of (23). We conjecture that $Y(t)$ is piece-wise constant, with $Y(t)=Y\left(T_{-}\right)$for $t \in[0, T)$, and $Y(t)=Y(T)$ for $t \in[T, \infty)$. This is based on the conjecture that both $\mu_{t}$ and $i_{t}^{q}$ can be set exogenously by the government, and that by (30) and (32) they only experience one discrete jump at time $T$ and are otherwise constant.

The solution for $J$ is derived in Appendix III. In the course of obtaining closed form solutions we verify the above mentioned conjectures. As for the closed form solutions, 
we find as before that $X=\beta^{-1}$. The consumption policy therefore continues to be given by equation (25). But the uncovered interest parity relationship (27) is now replaced by a portfolio balance relationship derived from (41):

$$
n_{t}^{q}+n_{t}^{m}=\frac{\left(i_{t}^{q}+\left(\sigma_{t}^{E}\right)^{2}-r-\varepsilon_{t}\right)}{\left(\sigma_{t}^{E}\right)^{2}} .
$$

In the following analysis, depending on the government's choice of $\mu$ and $\hat{\imath}^{q}$, this portfolio share could be anywhere between $-\infty$ and $+\infty$. We find that the case of $\left(n_{t}^{q}+n_{t}^{m}\right)>1$ is particularly interesting. In this case households borrow in foreign currency in order to hold domestic currency denominated assets, a common phenomenon in emerging markets. We will therefore analyze the model concentrating on this case, and leave an analysis of the remaining possibilities to the reader. The first implication of $\left(n_{t}^{q}+n_{t}^{m}\right)>1$ is negative expected government spending $E\left(d G_{t}\right) / d t<0$. To facilitate comparison with the economy under fiscal neutrality we impose an unchanged assumption (28) on the discount rate $\beta$. It is then clear by $(25),(43)$ and $E\left(d G_{t}\right) / d t<0$ that this will generate an increasing asset path and therefore an increasing consumption path. ${ }^{16}$

The dynamic behavior of this economy is governed by two constraints on the consumption path. The first is the cash constraint (6): $c_{t}=m_{t} / \alpha$. The second is a resource constraint through which fiscal spending is related to consumption. It consists of three relationships, the consumption optimality condition (25), $c_{t}=a_{t} \beta /\left(1+\alpha i_{t}^{q}\right)$, the current account equation (43), $d a_{t}=r a_{t} d t-c_{t} d t-d G_{t}$, and the government spending policy (37), $d G_{t}=a_{t}\left(n_{t}^{m}+n_{t}^{q}\right)\left[-\left(\sigma_{t}^{E}\right)^{2} d t+\sigma_{t}^{E} d B_{t}\right]$. Appendix III shows that the endogenous exchange rate drift and diffusion $\varepsilon_{t}$ and $\sigma_{t}^{E}$ can be determined as functions of exogenous parameters and of the two policy variables $\mu_{t}$ and $i_{t}^{q}$ by first differentiating the cash constraint and the consumption optimality condition using (43) and (37), and then equating drift and diffusion terms. For the drift term we obtain the following condition:

$$
\varepsilon_{t}=\mu_{t}+\left(\frac{c_{t}}{a_{t}}-r\right)
$$

\footnotetext{
16 The autonomous spending assumption mentioned in footnote 12 would avoid this.
} 
where $c_{t} / a_{t}=\beta /\left(1+\alpha i_{t}^{q}\right)$. Therefore in steady state, by (28), we have $\varepsilon_{t}=\mu_{t}$ : Because the rate of consumption out of assets equals the riskless rate $r$, the drift components of nominal money balances and the nominal exchange rate are equal. Note however that because $E\left(d G_{t}\right) / d t<0$, the asset stock and therefore consumption actually grow in expected terms. In other words, the expected real rate of return on assets $\tilde{r}$ is higher than $r$ because of government spending, and therefore $E\left(d c_{t} / c_{t}\right) / d t=\tilde{r}-r>0$ in steady state. This means that expected real money balances must grow at the same rate, $E\left(d m_{t} / m_{t}\right) / d t=\mu_{t}-\varepsilon_{t}+\left(\sigma_{t}^{E}\right)^{2}-\sigma_{t}^{E} \sigma^{M}=\tilde{r}-r>0$. As shown in Appendix III, the equilibrium value of $\sigma_{t}^{E}$ ensures that this is indeed the case. When $c_{t} / a_{t}$ falls below $r$, e.g. through an increase in $\hat{\imath}^{q}(\operatorname{see}(25))$, the consumption growth rate rises through faster asset accumulation. Real balances must then increase over time, $\mu_{t}>\varepsilon_{t}$.

The condition for the diffusion term $\sigma_{t}^{E}$ is:

$$
\sigma_{t}^{E} \sigma^{M}=\mu_{t}+\frac{\beta}{\left(1+\alpha i_{t}^{q}\right)}-i_{t}^{q}=r+\varepsilon_{t}-i_{t}^{q} .
$$

This condition guarantees that the rate of net increase of real money balances $\sigma_{t}^{M}-\sigma_{t}^{E}$ and therefore of consumption following a nominal money shock $d B_{t}$ equals the rate of net increase of total assets $-\left(n_{t}^{m}+n_{t}^{q}\right) \sigma_{t}^{E}$ and therefore of consumption. This is the basis for Figure 3 below, which plots exchange rate diffusion $\sigma_{t}^{E}$ against the domestic portfolio share $n_{t}^{m}+n_{t}^{q}$. Equation (48) shows that perfect asset substitutability and uncovered interest parity obtains as a limiting case - there is a choice of $i_{t}^{q}$ and $\mu_{t}$ that achieves $i_{t}^{q}=r+\varepsilon_{t}$ and $\sigma_{t}^{E}=0$. In that case $n_{t}^{m}+n_{t}^{q}$ in (46) is indeterminate. Slight positive / negative deviations from uncovered interest parity lead to near infinitely positive or negative portfolio shares. Slight positive deviations from uncovered interest parity are associated with $\left(n_{t}^{m}+n_{t}^{q}\right)>1$, and with a near zero but negative exchange rate diffusion coefficient $\sigma_{t}^{E}$. Note that we can rewrite the portfolio share entirely in terms of policy parameters as $n_{t}^{m}+n_{t}^{q}=1+\left(i_{t}^{q}-\mu_{t}-\beta /\left(1+\alpha i_{t}^{q}\right)\right)^{-1}$, which is decreasing in $i_{t}^{q}$. The widening of the interest differential due to higher $i_{t}^{q}$ is therefore more than offset by rising exchange rate 
volatility, leading to a contraction of the portfolio share towards one. By combining (47) and (48) we obtain the equivalent of equation (27):

$$
i_{t}^{q}+\sigma_{t}^{E} \sigma^{M}=r+\varepsilon_{t} .
$$

This is an arbitrage condition for domestic asset holders faced with fiscal-monetary risks. The nonzero and possibly time-varying risk premium $-\sigma_{t}^{E} \sigma^{M}$ in (49) and imperfect asset substitutability in (46) are due to the fact that the tax mechanism no longer provides a hedge against exchange rate risk. The absence of a financial market to hedge that risk therefore matters.

The risk premium has a very natural interpretation. We continue considering the case $\left(n_{t}^{m}+n_{t}^{q}\right)>1$ and $\sigma_{t}^{E}<0$. Given the cash constraint (6), a positive money shock therefore appreciates the exchange rate and increases real balances and consumption. This means that the marginal utility of consumption is lowest at the times when the domestic asset has the highest payoff. It therefore bears a higher interest rate. But this does not mean that a high interest rate prices an exogenous risk. In our setting the opposite is true, the interest rate is exogenous and exchange rate risk adjusts endogenously. We now turn to a more detailed discussion of this fiscal-monetary exchange rate adjustment mechanism.

Consider first a very large portfolio share $n_{t}^{m}+n_{t}^{q}$. Through the cash constraint a positive innovation to money $d B_{t}>0$ ceteris paribus increases real money balances and therefore desired consumption. But given the optimality condition (25), in order to be consistent with higher equilibrium consumption this must be accompanied by an increase in wealth $a_{t}$. By (43) this in turn requires a decrease in government spending according to (37). This is accomplished through an exchange rate adjustment, and it is in this sense that our theory is a fiscal theory of the exchange rate (to be precise, of high frequency changes in the exchange rate and therefore of the currency risk premium). The key to understanding exchange rate volatility in this model is that the size of the exchange rate jump required to bring about a given spending adjustment depends on the government's net domestic currency exposure 
to households. In particular, when the government has issued a large amount of domestic currency denominated liabilities the exchange rate must appreciate to reduce spending so as to offset the increase in the real value of government liabilities. As the domestic portfolio share decreases with higher interest rates, a larger change in the exchange rate is necessary to bring about any given adjustment in government spending. Because the volatility of the nominal money supply process is constant, this must result in higher exchange rate volatility. As exchange rate volatility goes to infinity, the volatility term in (46) dominates and drives the portfolio share $n_{t}^{m}+n_{t}^{q}$ towards 1 . Higher interest rates therefore lead to (potentially very large) increases in portfolio shares only if the increase takes rates from below to above uncovered interest parity. Otherwise they unambiguously reduce portfolio shares.

Higher interest rates increase the opportunity cost of holding domestic money and thereby reduce the rate of consumption out of current assets according to (25). This increases the rate of asset accumulation over time, an effect that is reinforced because, while higher interest rates reduce the portfolio share $n_{t}^{m}+n_{t}^{q}$, they can be shown to increase volatility so much that they further lower already negative expected government spending. Therefore higher interest rates increase the rate of growth of consumption.

We briefly remark on the empirical testability of our assumptions about fiscal behavior. We have shown that an increase in current consumption requires an increase in wealth and therefore a decrease in the present value of government spending. That wealth increase is brought about by an instantaneous change in the exchange rate that reallocates real portfolio wealth from the government to households. 


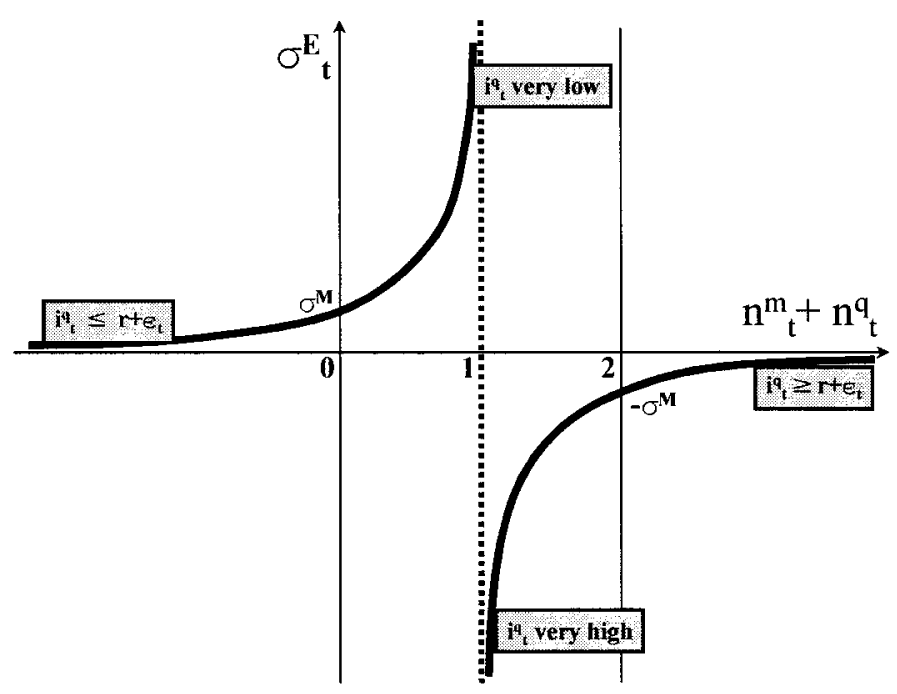

Figure 3 : Portfolio Shares and Exchange Rate Volatility

In our model the change in government spending is also modelled as instantaneous, but as discussed above this is done only for notational convenience. Our theory therefore does not imply that current government spending is countercyclical. It only implies that current wealth including capitalized expected future net government spending is procyclical. This is quite hard to test, and the main ground for accepting or rejecting our assumption has to be its intuitive plausibility. We certainly do not believe, especially for emerging markets, that the assumption of full lump-sum redistribution is more plausible.

We conclude by verifying that all integrability conditions are satisfied. Note first that the policy variables $\mu_{t}$ and $i_{t}^{q}$ are piece-wise constant by (30) and (32). The exchange rate drift and diffusion $\varepsilon_{t}$ and $\sigma_{t}^{E}$ therefore satisfy the integrability conditions because, apart from exogenous parameters and the exogenous $r$, they are functions only of $\mu_{t}$ and $i_{t}^{q}$ by (47) and (48). The drift of the tax process $\tau_{t}$ in equation (36) is absolutely integrable for a similar reason - the optimal portfolio shares in that equation are functions only of $\mu_{t}$ and $i_{t}^{q}$. 


\section{Monetary Policy}

\section{a. Stock Operations}

The effects of stock operations involving $M_{t}$ and/or $Q_{t}$ can be seen most clearly by expressing the key relationships in terms of nominal quantities:

$$
\begin{gathered}
\frac{M_{t}}{E_{t}}=\alpha c_{t}=a_{t} \frac{\alpha \beta}{1+\alpha i_{t}^{q}} \\
\frac{M_{t}+Q_{t}}{E_{t}}=\frac{i_{t}^{q}+\left(\sigma_{t}^{E}\left(i_{t}^{q}, \bar{\mu}\right)\right)^{2}-r-\varepsilon_{t}\left(i_{t}^{q}, \bar{\mu}\right)}{\left(\sigma_{t}^{E}\left(i_{t}^{q}, \bar{\mu}\right)\right)^{2}} .
\end{gathered}
$$

As in Section 2, full government compensation for exchange rate jumps in the form of international bond transfers is assumed. This implies that $a_{t}$ is always constant on impact. We also assume in what follows that $\mu_{t}$ is held constant at $\bar{\mu}$. Given $M_{t}$ and $Q_{t},(50)$ and (51) can then be solved for the two endogenous variables $E_{t}$ and $i_{t}^{q}$.

We start by discussing an unsterilized intervention that reduces $M$ through a sale of foreign exchange reserves $h$. This operation appreciates the nominal exchange rate according to (50). But unlike in the fiscal neutrality case it also affects the nominal interest rate. This is because the exchange rate effect reduces the real value of domestic currency bonds so much that the overall portfolio share $n_{t}^{m}+n_{t}^{q}$ rises. The interest rate $i^{q}$ must therefore fall to maintain portfolio balance.

An open market purchase of domestic bonds, a decrease in $Q$ and an equal increase in $M$, could be used to fully sterilize the effect of this intervention on the nominal money stock. By (50) this depreciates the nominal exchange rate, which by (51) lowers the portfolio share of domestic currency assets $n_{t}^{m}+n_{t}^{q}$. The interest rate $i_{t}^{q}$ must then rise to maintain portfolio balance. This in turn implies lower desired real money balances, and therefore a depreciation of the nominal exchange rate by proportionally more than the increase in the nominal money supply.

The size of the exchange rate appreciation and interest rate drop following a given 
contraction in money now depends on the market through which that contraction is implemented. The effects are larger if done through the domestic bond rather than the foreign exchange market. This is because under open market operations the portfolio share $n_{t}^{m}+n_{t}^{q}$ expands not just due to a nominal appreciation but also due to an expansion of the domestic nominal bond stock. This requires an even lower interest rate to establish portfolio balance, and thus by (50) it requires an even more appreciated exchange rate.

Sterilized intervention is simply the sum of an unsterilized intervention and a domestic open market operation that leaves the nominal money stock $M_{t}$ unchanged. Entirely unlike in the fiscal neutrality case, it now has nominal and real effects. We continue the above examples, where both $h_{t}$ and $Q_{t}$ contracted by equal amounts. To balance the portfolio for a given nominal exchange rate, the interest rate $i_{t}^{q}$ must rise. This gives rise to a small nominal depreciation, so that the equilibrium interest rate has to rise even further by (51). The higher $i_{t}^{q}$ in turn leads to a consumption drop on impact by $(25)$.

\section{b. Money Growth and Interest Rate Policies}

This subsection extends the above analysis by allowing for anticipated nonconstant paths of either $\mu_{t}$ or $i_{t}^{q}$, in particular policies (30) or (32). The former, illustrated in Figure 4, allows a comparison with the results of Section II.

Slower money growth, from (48) and (47), lowers exchange rate depreciation and diffusion. When we consider an initial steady state such that $\sigma_{t}^{E}<0$, this means that exchange rate volatility increases. This lowers the portfolio share $n_{t}^{m}+n_{t}^{q}$, but it can also be shown that it further lowers already negative expected government spending $-a_{t}\left(\sigma_{t}^{E}\right)^{2}\left(n_{t}^{m}+n_{t}^{q}\right)$. Expected consumption growth therefore increases. This is very different from the fiscal neutrality scenario of Figure 2. A change in money growth has a much smaller effect on consumption because the domestic interest rate is unaffected. On the other hand the reduction in inflation is more successful, it lasts until the end of the stabilization episode. 

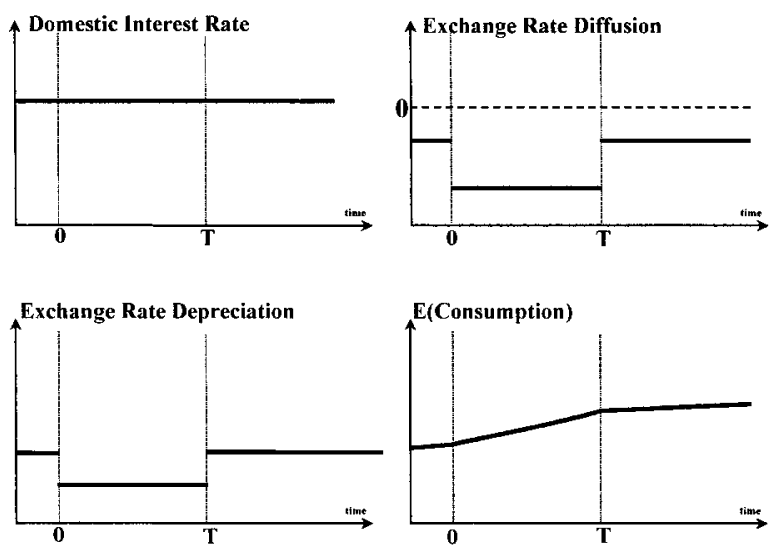

Figure 4 : Temporary Reduction in the Money Growth Rate

Policy (32), a temporary unanticipated increase in the nominal interest rate, is summarized in Figure 5. Both $\varepsilon_{t}$ and $\sigma_{t}^{E}$ fall. More importantly, there is an impact drop in consumption by (25). For similar reasons as the reduction in money growth, higher interest rates lower the portfolio share but further lower already negative expected government spending. Together with the faster rate of asset accumulation due to a lower consumption rate, this means that consumption growth increases for the duration of the policy. At the end of the high-interest period consumption takes an upward jump to a permanently higher level than before.

The idea that a central bank can use interest rates to reduce consumption demand and inflation can be found in many monetary models, particularly the recent sticky price literature on Taylor rules and inflation targeting. ${ }^{17}$ What distinguishes our model is that the interest rate can be chosen independently of the main nominal anchor, and therefore at a long-run level that is independent of steady state inflation. It can therefore have a much more sustained effect on consumption that is independent both of the degree of price stickiness and of the output distortion caused by deviations from the Friedman rule.

\footnotetext{
17 In our model lower inflation would be preceded by a discrete nominal depreciation on impact. This could be avoided if the initial drop in real money demand was accompanied by a one-off unsterilized intervention at the outset of the new policy.
} 

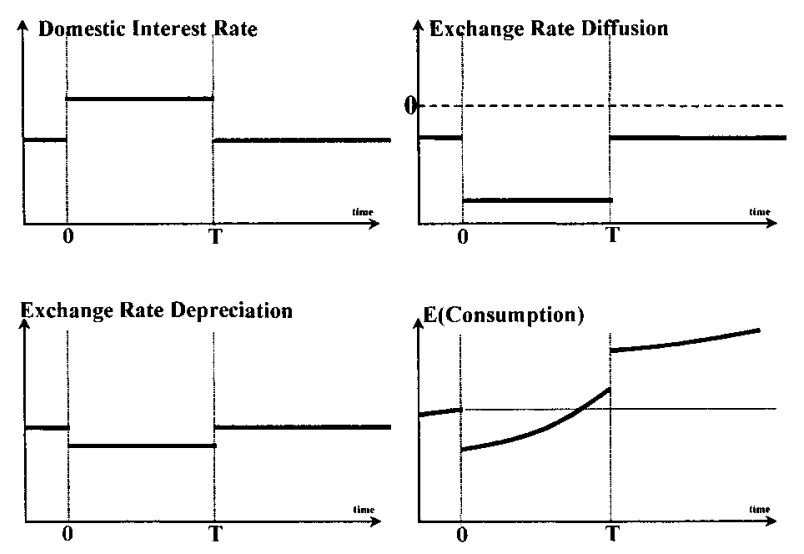

Figure 5: Temporary Increase in the Domestic Interest Rate

\section{CONCLUSION}

We have studied a general equilibrium monetary portfolio choice model of a small open economy with floating exchange rates. The model emphasizes the importance of fiscal policy for the number of instruments available to monetary policy, including its ability to affect allocations and prices through sterilized intervention. Conventional results were shown to depend on a particular assumption about fiscal policy, full lump-sum redistribution of stochastic seigniorage income. When such income is spent instead, two important results are obtained.

First, uncovered interest parity fails to hold. Large positive risk premia are possible, and are associated with a large portfolio share (greater than 1) of domestic assets in domestic agents' portfolios. However, the relationship between the portfolio share and the nominal interest rate is not monotonic - further increases in the interest rate reduce the portfolio share towards its limit of 1 .

Second, the monetary authority can set the domestic nominal interest rate and the money growth rate independently. Any intervention through domestic open market operations, whether they take place in the domestic money market or in the foreign exchange market 
as sterilized intervention, will generally affect both the interest rate and the level, growth rate and volatility of the exchange rate. Interest rate policy is therefore effective for demand management even under perfectly flexible prices. Changes in money growth are mainly effective in changing the rate of exchange rate depreciation. 


\section{Returns on Assets}

The foreign interest rate $r$ is non-stochastic by assumption. Therefore the return on foreign bonds is given by

$$
d r_{t}^{b}=r d t
$$

The return on real money balances is derived using Itô's law to differentiate $M_{t} / E_{t}$ holding $M_{t}$ constant:

$$
d r_{t}^{m}=M_{t} d\left(\frac{1}{E_{t}}\right)=M_{t}\left[\frac{-1}{E_{t}^{2}} \varepsilon_{t} E_{t}+\frac{1}{2}\left(\sigma_{t}^{E}\right)^{2} E_{t}^{2} \frac{2}{E_{t}^{3}}\right] d t+M_{t}\left[\frac{-1}{E_{t}^{2}} \sigma_{t}^{E} E_{t}\right] d B_{t}
$$

which yields the return

$$
d r_{t}^{m}=\left(-\varepsilon_{t}+\left(\sigma_{t}^{E}\right)^{2}\right) d t-\sigma_{t}^{E} d B_{t}
$$

The real return on the domestic bond is given by its nominal interest rate $i_{t}^{q}$, minus the change in the international value of domestic money as in (A.2). We have

$$
d r_{t}^{q}=\left(i_{t}^{q}-\varepsilon_{t}+\left(\sigma_{t}^{E}\right)^{2}\right) d t-\sigma_{t}^{E} d B_{t}
$$




\section{Value Function - No Aggregate Exchange Risk}

This Appendix derives the closed form expression for the conjectured value function $V\left(a_{t}, t\right)=e^{-\beta t} J\left(a_{t}, t\right)=e^{-\beta t} X\left[\ln \left(a_{t}\right)+\ln (Y(t))\right]$. Substitute the conjecture and the government policy rules into the Bellman equation (10) to get:

$$
\begin{aligned}
\beta X \ln \left(a_{t}\right)+\beta X \ln (Y(t))-X(\ln (\dot{Y}(t)))= & \ln \left(a_{t}\right)-\ln (X)-\ln \left(1+\alpha i_{t}^{q}\right) \\
& +X\left[r-X^{-1}\left(1+\alpha i_{t}^{q}\right)^{-1}\right] .
\end{aligned}
$$

Equating terms on $\ln \left(a_{t}\right)$ yields

$$
X=\beta^{-1}
$$

Therefore

$$
c_{t}=a_{t} \frac{\beta}{\left(1+\alpha i_{t}^{q}\right)} \quad, \quad n_{m_{t}}=\frac{\alpha \beta}{\left(1+\alpha i_{t}^{q}\right)} \quad, \quad n_{q_{t}}=\psi n_{m_{t}} \quad .
$$

We are left with a differential equation in $Y(t)$ as follows:

$$
X(\dot{Y}(t) / Y(t))=\ln (Y(t))-\ln (\beta)-r / \beta+\ln \left(1+\alpha i_{t}^{q}\right)+\left(1+\alpha i_{t}^{q}\right)^{-1} .
$$

To verify our conjecture that $Y(t)$ is a function only of exogenous parameters, including $\mu_{t}$, and of time, we need to first solve for the equilibrium path of $i_{t}^{q}$. Note that equation (B.2) shows that consumption is not stochastic, because $a_{t}$ in the current account equation (21) evolves deterministically. Then by (6) demand for real money balances does not fluctuate with stochastic shocks. This result can be used to determine the variance of exchange rate shocks. We use Itô's lemma to determine the evolution of the real money supply $m_{t}=\frac{M_{t}}{E_{t}}$ as

$$
d m_{t}=m_{t}\left(\mu_{t}-\varepsilon_{t}+\left(\sigma_{t}^{E}\right)^{2}-\sigma_{t}^{E} \sigma^{M}\right) d t+m_{t}\left(\sigma^{M}-\sigma_{t}^{E}\right) d B_{t} .
$$

The above argument implies that the diffusion of the exchange rate process must be a constant and equal to the diffusion of the money supply:

$$
\sigma_{t}^{E}=\sigma^{M} \forall t
$$

We therefore obtain

$$
\frac{\dot{m}_{t}}{m_{t}}=\frac{\dot{c}_{t}}{c_{t}}=\left(\mu-\varepsilon_{t}\right)
$$


At the same time differentiation of $c_{t}$ in (B.2) generates

$$
\frac{\dot{c}_{t}}{c_{t}}=\frac{\dot{a}_{t}}{a_{t}}-\frac{\alpha}{1+\alpha i_{t}^{q}} i_{t}^{q}
$$

which when combined with (B.2), (B.5), (21) and (27) produces the following differential equation for the nominal interest rate:

$$
\dot{i}_{t}^{q}=\frac{1+\alpha i_{t}^{q}}{\alpha}\left(i_{t}^{q}+\left(\sigma^{M}\right)^{2}-\mu_{t}\right)-\frac{\beta}{\alpha} .
$$

As discussed in the text, we choose a value for the discount rate $\beta$ such that consumption is constant in steady state, so that $\bar{\varepsilon}=\bar{\mu}$. Noting that $\left(i_{t}^{q}+\left(\sigma^{M}\right)^{2}-\mu_{t}\right)=r+\varepsilon_{t}-\mu_{t}$, equation (B.6) exhibits uniqueness of equilibrium paths because

$$
\left.\frac{\partial \dot{i}_{t}^{q}}{\partial i_{t}^{q}}\right|_{i_{t}^{q}=0}=\frac{1+\alpha \bar{\imath}^{q}}{\alpha}+r>0
$$

Equation (B.6) shows that the path of $i_{t}^{q}$ can be computed as the solution of a nonlinear first order differential equation that depends only on exogenous terms, so that $i_{t}^{q}$ is a function of only these exogenous terms and time. The terminal condition is $i_{T}^{q}=r+\mu_{H}-\left(\sigma^{M}\right)^{2}$. Consequently the path for $Y(t)$ can be obtained from equation (B.3) as a function of exogenous terms and time, with terminal condition $Y(T)=r$.

We have now solved for a candidate value function $V\left(a_{t}, t\right)$ and the associated feedback controls $\left(n_{t}^{q *}, n_{t}^{m *}\right)$ and wealth process $a_{t}^{*}$. As is common in this literature it is not possible to state general sufficiency conditions for this approach. Instead we proceed by verification. Note first that our solutions solve the problem

$$
\sup _{n_{t}^{m}, n_{t}^{q}}\left\{\ln \left(n_{t}^{m} a_{t} / \alpha\right)+D J\left(a_{t}, t\right)\right\}=0
$$

where

$$
D J\left(a_{t}, t\right)=J_{a}\left(a_{t}, t\right) g\left(a_{t}, n_{t}^{m}, n_{t}^{q}\right)+\frac{1}{2} J_{a a}\left(a_{t}, t\right) h\left(a_{t}, n_{t}^{m}, n_{t}^{q}\right)-\beta J\left(a_{t}, t\right)+\dot{j},
$$

where the functions $g(., .,$.$) and h(., .,$.$) for our specific problem are$

$$
\begin{aligned}
& g\left(a_{t}, n_{t}^{m}, n_{t}^{q}\right)=a_{t}\left(r-\frac{n_{t}^{m}}{\alpha}\right), \\
& h\left(a_{t}, n_{t}^{m}, n_{t}^{q}\right)=0 .
\end{aligned}
$$


Now let $\left(n_{t}^{q}, n_{t}^{m}\right)$ be an arbitrary admissible control for initial wealth $a_{0}$ and let $a_{t}$ be the associated wealth process. By Itô's formula

$$
\begin{aligned}
e^{-\beta t} J\left(a_{t}, t\right) & =J\left(a_{0}, 0\right)+\int_{0}^{t} e^{-\beta s} D J\left(a_{s}, s\right) d s+\int_{0}^{t} e^{-\beta s} \psi_{s} d B_{s} \\
\text { where } \psi_{t} & =J_{a}\left(a_{t}, t\right) h\left(a_{t}, n_{t}^{m}, n_{t}^{q}\right) .
\end{aligned}
$$

We proceed to take limits and expectations of this equation. As shown in Duffie (1996), a crucial step in the following argument is to demonstrate that $E\left(\int_{0}^{t} e^{-\beta s} \psi_{s} d B_{s}\right)=0$. To do so one needs to demonstrate that $\int_{0}^{t} e^{-\beta s} \psi_{s} d B_{s}$ is a martingale, which requires the condition $E\left[\int_{0}^{t}\left(e^{-\beta s} \psi_{s}\right)^{2} d s\right]<\infty$. In the present context this is trivially satisfied because $h(., .,)=$.0 and therefore $\psi_{t}=0 \forall t$. Therefore we have

$$
\begin{aligned}
\lim _{t \rightarrow \infty} E_{0}\left\{e^{-\beta t} J\left(a_{t}, t\right)\right\} & =\lim _{t \rightarrow \infty} E_{0}\left\{J\left(a_{0}, 0\right)+\int_{0}^{t} e^{-\beta s} D J\left(a_{s}, s\right) d s\right\} \\
& =J\left(a_{0}, 0\right)+\int_{0}^{\infty} e^{-\beta s} D J\left(a_{s}, s\right) d s .
\end{aligned}
$$

The left-hand side is zero by the transversality condition (11). Because the chosen control is arbitrary, (B.8) implies that

$$
\ln \left(n_{t}^{m} a_{t} / \alpha\right) \leq-D J\left(a_{t}, t\right)
$$

and therefore

$$
J\left(a_{0}, 0\right) \geq \int_{0}^{\infty} e^{-\beta s} \ln \left(n_{s}^{m} a_{s} / \alpha\right) d s
$$

Our candidate solution for the value function therefore dominates the value obtained from any other admissible control process. Then the optimal control processes in (B.2), $n_{t}^{q}\left(a_{t}\right), n_{t}^{m}\left(a_{t}\right)$, can be combined with (21) to obtain the associated path of $a_{t}^{*}$. This can in turn be used to obtain paths for the control processes $\left(n_{t}^{q *}, n_{t}^{m *}\right)$ themselves. For these paths we have, by construction

$$
J\left(a_{0}, 0\right)=\int_{0}^{\infty} e^{-\beta s} \ln \left(n_{t}^{m *} a_{t}^{*} / \alpha\right) d s
$$




\section{Value Function - Aggregate Exchange Risk}

We use conjecture (45), including piece-wise constancy of $Y(t)$. Substitutions of the optimal policies into the Hamilton-Jacobi-Bellman equation (40) now produce the following:

$$
\begin{aligned}
& \beta X \ln \left(a_{t}\right)+\beta X \ln (Y(t)) \\
= & \ln \left(a_{t}\right)-\ln (X)-\ln \left(1+\alpha i_{t}^{q}\right) \\
& +X\left[i_{t}^{q}+\left(\sigma_{t}^{E}\right)^{2}-\varepsilon_{t}-X^{-1}\left(1+\alpha i_{t}^{q}\right)^{-1}\right]-\frac{1}{2} X \frac{\left(i_{t}^{q}+\left(\sigma_{t}^{E}\right)^{2}-r-\varepsilon_{t}\right)^{2}}{\left(\sigma_{t}^{E}\right)^{2}} .
\end{aligned}
$$

Equalizing coefficients on $\ln \left(a_{t}\right)$ we get:

$$
X=\beta^{-1} .
$$

Furthermore,

$$
\begin{aligned}
Y(t)= & \ln \left(\frac{\beta}{1+\alpha i_{t}^{q}}\right)+\frac{1}{\beta}\left(i_{t}^{q}+\left(\sigma_{t}^{E}\right)^{2}-\varepsilon_{t}-\frac{\beta}{1+\alpha i_{t}^{q}}\right) \\
& -\frac{1}{2 \beta} \frac{\left(i_{t}^{q}+\left(\sigma_{t}^{E}\right)^{2}-r-\varepsilon_{t}\right)^{2}}{\left(\sigma_{t}^{E}\right)^{2}} .
\end{aligned}
$$

We now show that $Y(t)$ is indeed piece-wise constant for $t \in[0, T)$ and $t \in[T, \infty)$ as conjectured. To do so we demonstrate that our result for $X$ and the fact that $i_{t}^{q}$ and $\mu_{t}$ are piece-wise constant implies that $\varepsilon_{t}$ and $\sigma_{t}^{E}$ are piece-wise constant. Using the result for $X$ we obtain the consumption policy function as

$$
c_{t}=a_{t} \frac{\beta}{\left(1+\alpha i_{t}^{q}\right)} .
$$

Now differentiate this function, again using the fact that $i_{t}^{q}$ is piecewise constant:

$$
\frac{d c_{t}}{c_{t}}=\frac{d a_{t}}{a_{t}}=\left[i_{t}^{q}+\left(\sigma_{t}^{E}\right)^{2}-\varepsilon_{t}-\frac{\beta}{\left(1+\alpha i_{t}^{q}\right)}\right] d t-\frac{\left(i_{t}^{q}+\left(\sigma_{t}^{E}\right)^{2}-r-\varepsilon_{t}\right)}{\sigma_{t}^{E}} d B_{t} \quad \forall t \neq 0_{-}, T_{-} .
$$

Recall the evolution equation for real money balances:

$$
\frac{d m_{t}}{m_{t}}=\frac{d c_{t}}{c_{t}}=\left(\mu_{t}-\varepsilon_{t}+\left(\sigma_{t}^{E}\right)^{2}-\sigma_{t}^{E} \sigma^{M}\right) d t+\left(\sigma^{M}-\sigma_{t}^{E}\right) d B_{t} \quad \forall t \neq 0_{-}, T_{-}
$$


We equate $d t$ and $d B_{t}$ terms in (C.4) and (C.5) and solve for $\varepsilon_{t}$ and $\sigma_{t}^{E}$ as functions of the exogenous variables as follows:

$$
\begin{aligned}
\varepsilon_{t} & =\mu_{t}+\frac{\beta}{\left(1+\alpha i_{t}^{q}\right)}-r, \\
\sigma_{t}^{E} \sigma^{M} & =\left(\mu_{t}+\frac{\beta}{\left(1+\alpha i_{t}^{q}\right)}-i_{t}^{q}\right) .
\end{aligned}
$$

This verifies that if $i_{t}^{q}$ and $\mu$ are piecewise constant government policies then $\varepsilon_{t}$ and $\sigma_{t}^{E}$ are piecewise constant as well. Substituting (C.6) into (C.2) we validate the conjectured form for the value function, including the piece-wise continuity, with a jump at $T$, of $Y(t)$.

Verification proceeds as in Appendix II. It amounts to verifying the validity of $E\left[\int_{0}^{t}\left(e^{-\beta s} \psi_{s}\right)^{2} d s\right]<\infty$, where $\psi_{s}=J_{a} a_{t}^{2}\left(\sigma_{t}^{E}\right)^{2}\left(n_{t}^{m}+n_{t}^{q}\right)^{2}$. At the optimum we know $\left(n_{t}^{m}+n_{t}^{q}\right)=\frac{\left(i_{t}^{q}+\left(\sigma_{t}^{E}\right)^{2}-r-\varepsilon_{t}\right)}{\left(\sigma_{t}^{E}\right)^{2}}$ and $J_{a}=\left(\beta a_{t}\right)^{-1}$. We recall that $\sigma_{t}^{E}, i_{t}^{q}, \varepsilon_{t}$ are piecewise constant and have bounded jumps at discontinuities. Further the process $a_{t}$ follows a geometric Brownian Motion, which makes it log-normally distributed with bounded variance. Therefore the square integrability condition is satisfied. 


\section{References}

[1] Aizenman, J. (1989), 'Country Risk, Incomplete Information and Taxes on International Borrowing', Economic Journal, 99, 147-161.

[2] Backus, D.K. and Kehoe, P.J. (1989), 'On the Denomination of Government Debt - A Critique of the Portfolio Balance Approach', Journal of Monetary Economics, 23, 359-376.

[3] Bakshi, G.S. and Chen, Z. (1997), 'Equilibrium Valuation of Foreign Exchange Claims', Journal of Finance, 52, 799-826.

[4] Bansal, R. and Dahlquist, M. (2000), 'The Forward Premium Puzzle: Different Tales from Developed and Emerging Economies', Journal of International Economics, 51(1), 115-144.

[5] Branson, W.H. and Henderson, D.W. (1985), 'The Specification and Influence of Asset Markets', Ch. 15 in: Handbook of International Economics, vol. 2.

[6] Chamley, C. and Ptolemarchakis, H. (1984), 'Assets, General Equilibrium, and the Neutrality of Money', Review of Economic Studies, 51, 129-138.

[7] Chow, G.C. (1979), 'Optimum Control of Stochastic Differential Equation Systems', Journal of Economic Dynamics and Control, 1, 143-175.

[8] Cox, J.C., Ingersoll, J.E. and Ross, S.A. (1985), 'An Intertemporal General Equilibrium Model of Asset Prices', Econometrica, 53(2), 363-384.

[9] Duffie, D. (1996), Dynamic Asset Pricing Theory, 2nd edition, Princeton University Press, Princeton, NJ.

[10] Dumas, B. and Uppal, R. (2000), "Global Diversification, Growth and Welfare with Imperfectly Integrated Markets for Goods", Manuscript, INSEAD and MIT.

[11] Eaton, J. and Gersovitz, M. (1981), "Debt with Potential Repudiation: Theoretical and Empirical Analysis", Review of Economic Studies, 48, 289-309.

[12] Edison, H.J. (1993), 'The Effectiveness of Central Bank Intervention: A Survey of the Literature since 1982', Special Papers in International Economics No. 18., Princeton University, Princeton, NJ.

[13] Devereux, M.B. and Engel, C. (1998), 'Fixed versus Floating Exchange Rates: How Price Setting Affects the Optimal Choice of Exchange Rate Regime', NBER Working Paper No. 6867.

[14] Engel, C. (1992), 'On the Foreign Exchange Risk Premium in a General Equilibrium Model', Journal of International Economics, 32, 305-319. 
[15] Engel, C. (1999), 'On the Foreign Exchange Risk Premium in Sticky-Price General Equilibrium Models', NBER Working Paper No. 7067.

[16] Feenstra, R.C. (1986), 'Functional Equivalence between Liquidity Costs and the Utility of Money', Journal of Monetary Economics, 17, 271-291.

[17] Fleming, W.H. and Rishel, R.W. (1975), Deterministic and Stochastic Optimal Control, Springer Verlag, New York, NY.

[18] Gavin, M. and Perotti, R. (1997), 'Fiscal Policy in Latin America', (Manuscript, Inter-American Development Bank and Columbia University).

[19] Grinols, E.L. and Turnovsky, S.J. (1994), 'Exchange rate determination and asset prices in a stochastic small open economy', Journal of International Economics, 36, 75-97.

[20] Karatzas, I. and Shreve, S.E. (1991), Brownian Motion and Stochastic Calculus, 2nd edition, Springer Verlag, New York, NY.

[21] Kehoe, P.J. and Perri, F. (2001), 'International Business Cycles with Endogenous Incomplete Markets', Econometrica (forthcoming).

[22] Kletzer, K.M. and Wright, B.D. (2000), 'Sovereign Debt as Intertemporal Barter', American Economic Review, 90(3), 621-639.

[23] Lucas, Robert E. jr. (1982), 'Interest Rates and Currency Prices in a Two-Country World', Journal of Monetary Economics, 10, 335-359.

[24] Lucas, Robert E. jr. (1990), 'Liquidity and Interest Rates', Journal of Economic Theory, 50, 237-264.

[25] Malliaris, A.G. and Brock, W.A. (1982), Stochastic Methods in Economics and Finance, 1st edition, Advanced Textbooks in Economics, Volume 17, Elsevier, Amsterdam.

[26] Merton, R.C. (1969), 'Lifetime Portfolio Selection under Uncertainty: The ContinuousTime Case', The Review of Economics and Statistics, 51, 239-246.

[27] Merton, R.C. (1971), 'Optimum Consumption and Portfolio Rules in a Continuous-Time Model', Journal of Economic Theory, 3, 373-413.

[28] Montiel, P.J. (1993), 'Capital Mobility in Developing Countries', The World Bank Working Paper Series 1103.

[29] Obstfeld, M. (1982), 'The Capitalization of Income Streams and the Effects of Open-Market Policy under Fixed Exchange Rates', Journal of Monetary Economics, 9, 87-98.

[30] Obstfeld, M. (1987), 'Peso Problems, Bubbles, and Risk in the Empirical Assessment of Exchange-Rate Behavior', NBER Working Paper No. 2203. 
[31] Obstfeld, M. and Rogoff, K. (1996), Foundations of International Macroeconomics, 1 st edition, MIT Press, Cambridge, MA.

[32] Obstfeld, M. and Rogoff, K. (1998), 'Risk and Exchange Rates', NBER Working Paper No. 6694.

[33] Obstfeld, M. and Rogoff, K. (2000), 'New Directions for Stochastic Open Economy Models', Journal of International Economics, 50, 117-153.

[34] Sargent, T.J. and Smith, B.D. (1987), 'The Irrelevance of Government Foreign Exchange Operations', in: Helpman, E., Razin, A. and Sadka, E., eds., Economic Effects of the Government Budget, Cambridge, Mass. and London: MIT Press.

[35] Sargent, T.J. and Smith, B.D. (1988), 'Irrelevance of Open Market Operations in Some Economies with Government Currency Being Dominated in Rate of Return', American Economic Review, 77(1), 78-92.

[36] Stulz, R.M. (1983), 'The Demand for Foreign Bonds', Journal of International Economics, 15, 225-238.

[37] Stulz, R.M. (1984), 'Currency Preferences, Purchasing Power Risks, and the Determination of Exchange Rates in an Optimizing Model', Journal of Money, Credit and Banking, 16(3), 302-316.

[38] Stulz, R.M. (1987), 'An Equilibrium Model of Exchange Rate Determination and Asset Pricing with Nontraded Goods and Imperfect Information', Journal of Political Economy, 95(5), 1024-1040.

[39] Stulz, R.M. (1988), 'Capital Mobility and the Current Account', Journal of International Money and Finance, 7, 167-180.

[40] Uribe, M. (2001), 'A Fiscal Theory of Sovereign Risk', (Manuscript, University of Pennsylvania).

[41] Wallace, N. (1981), 'A Modigliani-Miller Theorem for Open Market Operations', American Economic Review, 71, 267-274.

[42] Zapatero, F. (1995), 'Equilibrium Asset Prices and Exchange Rates', Journal of Economic Dynamics and Control, 19, 787-811. 